\title{
Profiling the Cymbopogon nardus Ethanol Extract and Its Antifungal Potential against Candida Species with Different Patterns of Resistance
}

\author{
Luciani G. de Toledo, ${ }^{\oplus a, b}$ Matheus A. S. Ramos, ${ }^{\circledR a}$ Larissa Spósito, ${ }^{\circledR a}$ Elza M. Castilho, ${ }^{\oplus b}$ \\ Fernando R. Pavan, ${ }^{\circledR a}$ Érica O. Lopes, ${ }^{\circledR a}$ Isabel C. da Silva, ${ }^{\circledR a}$ Guilherme J. Zocolo, ${ }^{\circledR}$ c \\ Paulo R. V. Ribeiro, ${ }^{\circledR c}$ Fernando B. Oda, ${ }^{\circledR d}$ Juhan A. S. Pereira, ${ }^{d}$ André G. dos Santos, ${ }^{\odot d}$ \\ Taís M. Bauab ${ }^{\circledR a}$ and Margarete T. G. de Almeida ${ }^{\circledR} * b$ \\ ${ }^{a}$ Departamento de Ciências Biológicas, Faculdade de Ciências Farmacêuticas, \\ Universidade Estadual Paulista (Unesp), 14800-903 Araraquara-SP, Brazil \\ ${ }^{b}$ Departamento de Doenças Infecciosas, Faculdade de Medicina de São José do Rio Preto (FAMERP), \\ 15090-000 São José do Rio Preto-SP, Brazil

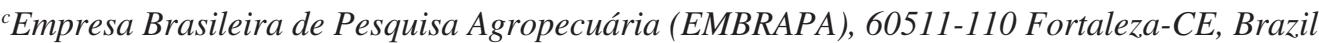 \\ ${ }^{d}$ Departamento de Princípios Ativos Naturais e Toxicologia, Faculdade de Ciências Farmacêuticas, \\ Universidade Estadual Paulista (Unesp), 14800-903 Araraquara-SP, Brazil
}

\begin{abstract}
The essential oil of Cymbopogon nardus, citronella, has been extensively studied. However, the chemical and biological properties of the ethanolic extract (EE) of $C$. nardus have not been evaluated. The aim of this study was to characterize the chemical composition of the EE of C. nardus and its active fraction (FrD). Moreover, the cytotoxic and antifungal properties of these extracts against Candida species with different resistance profiles to conventional drugs were evaluated. The compounds identified in EE were mono- $C$ - and di- $C$-glycosyl flavones and phenylpropanoid glycosides. Phenylpropanoid glycosides were identified in FrD. EE showed antifungal activity, with minimum inhibitory concentration (MIC) values ranging from 62.5 to $500 \mu \mathrm{g} \mathrm{mL}^{-1}$. FrD was more effective against $C$. glabrata, as evidenced by the lowest MIC value $\left(15.6 \mu \mathrm{g} \mathrm{mL} \mathrm{m}^{-1}\right)$. EE inhibited yeast growth similar to amphotericin-B, as demonstrated by similar time-kill curves. EE inhibited C. albicans hyphae formation and mature biofilm of C. albicans, C. krusei and C. parapsilosis. The results of the chemical and biological analyses of $\mathrm{EE}$ and its fractions provided novel information and may contribute to control of infections caused by Candida species.
\end{abstract}

Keywords: Cymbopogon nardus, ethanol extract, flavones, phenylpropanoids, antifungal activity, Candida spp.

\section{Introduction}

The Cymbopogon genus is an important source of compounds with pharmacological properties. Cymbopogon nardus (L.) Rendle (Poaceae), commonly known as citronella, is native to Ceylon, and is cultivated in subtropical and tropical regions of Asia, Africa, and America. The essential oil and the ethanolic extract (EE) of citronella leaves have been traditionally used as insect repellents. Moreover, in Thailand, an infusion of citronella leaves is used to treat flatulence, dyspepsia, and abdominal cramps. $^{1}$

*e-mail: margarete@ famerp.br
C. citratus exerts anti-inflammatory, antifungal, ${ }^{2}$ antibacterial, ${ }^{3}$ and anthelmintic ${ }^{4}$ activities, and the essential oil from $C$. nardus can repel Aedes aegypti, Culex quinquefasciatus, and Anopheles dirus mosquitoes, ${ }^{5}$ and exerts antibacterial ${ }^{6}$ and antifungal ${ }^{7}$ activities.

The antifungal potential of the essential oil of C. nardus against species of Candida has been studied with satisfactory results. ${ }^{7,8}$ These positive results were likely due to its bioactive properties, particularly considering that this essential oil contains secondary monoterpene metabolites such as citronellal, citronellol, and geraniol. ${ }^{7}$ However, the chemical composition and antifungal activity of EE of $C$. nardus leaves against clinical strains has not been well-characterized. 
Some plant extracts have been evaluated against fungi ${ }^{9}{ }^{10}$ because of the presence of secondary metabolites with antimicrobial properties, such as phenols, flavonoids, terpenes, and alkaloids. ${ }^{11} \mathrm{~A}$ study ${ }^{12}$ described the in vitro fungistatic and fungicidal activity of a hydroethanolic extract of C. nardus against Microsporum canis and Trichophyton rubrum isolated from animals and the home environment.

Classical treatments for fungal infections include polyenes, azoles, and echinocandins. However, these treatments induce significant side effects. The side effects associated with synthetic antifungal agents promote aggravation of the disease state, since the side effects are typically related to hepatotoxicity and renal dysfunction. ${ }^{13}$ Moreover, the lack of alternative treatment options is problematic in the case of drug resistance. ${ }^{14}$

Candida has emerged as important species associated with opportunistic infections, resulting in a significant public health issue. ${ }^{15}$ Several predisposing factors including immunodeficiency, antineoplastic therapy, organ transplantation, endocrine dysfunction, and prolonged antibiotic use increase susceptibility to Candida infection. ${ }^{16}$

Candida spp. infections range from superficial infections, such as vulvovaginal candidiasis, esophageal or oropharyngeal candidiasis, and disseminated candidiasis. ${ }^{17}$ Candida infections are associated with high morbidity and mortality rates in nosocomial bloodstream infections. ${ }^{18}$

Several virulence factors associated with Candida spp. include morphological transition between yeast and hyphae, ability to defend against the host immune system, adhesion, biofilm formation, and production of harmful enzymes such as hydrolytic proteases, phospholipases, and hemolysin. ${ }^{19}$

This study aimed to evaluate for the first time the chemical composition and antifungal activity of $C$. nardus against standard and clinical strains of Candida species with different biological virulence profiles and antifungal susceptibility.

\section{Experimental}

Plant material

C. nardus leaves were collected in the morning (July 2013), in the Garden of Toxic and Medicinal Plants: Profa Dra Célia Cebrian de Araújo Reis (longitude $48.20170^{\circ} \mathrm{W}$, latitude $21.81453^{\circ} \mathrm{S}$ ), Universidade Estadual Paulista (Unesp), Araraquara, São Paulo, Brazil. A voucher specimen (HRCB-60752) was deposited at Herbarium Rioclarense of the Institute of Biosciences (Unesp, Rio Claro, São Paulo, Brazil). This work was approved by the National System for the Management of
Genetic Heritage and Associated Traditional Knowledge (SisGen) under license No. A2B917A and AF35617/CNPJ 48.031.918/0001-24.

\section{Ethanolic extract (EE) preparation}

Dried and powered leaves $(500 \mathrm{~g})$ were extracted by sonication in ethanol (99\%) (Hexis, Jundiaí, São Paulo, Brazil) in four steps $(2.0,1.5,1.5$, and $0.5 \mathrm{~L}$; 20 min per step) with occasional agitation. All extracted solutions were filtered, mixed, concentrated using a rotary evaporator, dried in a fume hood and then in a desiccator with silica gel. The yield of dried EE was $1.35 \%$.

\section{Fractionation of EE by solid phase extraction (SPE)}

EE (2.3 g) was loaded onto a glass column containing silica gel (60-200 $\mu \mathrm{m}$; height: $10 \mathrm{~cm}$, $\left(\right.$ Merck $^{\circledR} \mathrm{KGaA}$, Darmstadt, Germany). Elution was performed under reduced pressure using hexane:ethyl acetate $(9: 1, \mathrm{v} / \mathrm{v})$, hexane:ethyl acetate $(7: 3, v / v)$, ethyl acetate $(100 \%)$, ethyl acetate:methanol $(9: 1, \mathrm{v} / \mathrm{v})$, and methanol $(100 \%)$, yielding 10 fractions (40 mL each) (two per eluent).

The obtained SPE fractions (Fr) $\left(5.0 \mathrm{mg} \mathrm{mL}^{-1}\right.$; ethyl acetate) were analyzed by thin layer chromatography (TLC) on glass plates with silica gel (Sigma-Aldrich ${ }^{\circledR}$, Saint Louis, MO, USA; $20 \times 20 ; 0.25 \mathrm{~mm}$ ). The mobile phases were hexane:ethyl acetate:isopropanol (70:28:2, v/v/v), $n$-butanol:acetic acid:water $(67: 30: 3, \mathrm{v} / \mathrm{v} / \mathrm{v})$, and chloroform:ethyl acetate (60:40, v/v), and 10\% aqueous sulfuric acid was used as the spray reagent. Comparison of the Fr chemical profiles by TLC analysis indicated that seven fractions with different profiles could be pooled (FrA, FrB, FrC, FrD, FrE, FrF, and FrG). The fractions (weight; eluent) were as follows: FrA (0.108 g; hexane:ethyl acetate 9:1), $\mathrm{FrB}$ (0.067 g; hexane:ethyl acetate 9:1), $\mathrm{FrC}$ (0.471 g; hexane:ethyl acetate 7:3), FrD (0.322 g; ethyl acetate), $\mathrm{FrE}$ (0.096 g; ethyl acetate:methanol 9:1), FrF (0.078 g; ethyl acetate:methanol 9:1), and FrG (0.446 g; methanol). FrD was selected for chemical analysis since this fraction showed the best anti-Candida activity, mainly against $C$. glabrata. All solvents used were of analytical grade and purchased commercially (Synth ${ }^{\circledast}$, Diadema, São Paulo, Brazil).

Ultra-performance liquid chromatography electrospray ionization quadrupole time-of-flight mass spectrometry (UPLC-ESI-QTOF-MSE) analysis

Prior to analyses, $10.0 \mathrm{mg}$ each of EE and FrD samples were subjected to SPE using Phenomenex ${ }^{\circledR} \mathrm{Strata}^{\mathrm{TM}} \mathrm{C} 18$-E 
cartridges (Torrance, CA, USA, $15 \times 10 \mathrm{~mm} ; 55 \mu \mathrm{m}$ ). Samples were eluted with $5.0 \mathrm{~mL}$ of methanol:water $(95: 5, \mathrm{v} / \mathrm{v})$. The obtained solutions $(5 \mathrm{~mL})$ were dried in a desiccator (silica gel under reduced pressure) and the residues were dissolved in $1.0 \mathrm{~mL}$ of methanol, then filtered $\left(0.22 \mu \mathrm{m}\right.$, PVDF Merck Millipore ${ }^{\circledR}, \mathrm{KGaA}$, Darmstadt, Germany) prior to analysis.

Chemical analyses of EE and FrD were performed using an Acquity UPLC (Waters Corporation ${ }^{\circledR}$, Milford, Massachusetts, USA) coupled to a quadrupole/time of flight system (XEVO-QToF, Waters Corporation ${ }^{\circledR}$, Milford, Massachusetts, USA). The mobile phases were water with $0.1 \%$ formic acid (A) and acetonitrile with $0.1 \%$ formic acid (B). The gradient program was as follows: (0-15) $\mathrm{min}, 2-95 \% \mathrm{~B}$; (15.1-17) $\mathrm{min}, 100 \%$ B; (17.1-19.1) min, 2\% B. Separation was performed using a Waters Acquity UPLC BEH C18 column (Milford, MA, USA, $150 \times 2.1 \mathrm{~mm}, 1.7 \mu \mathrm{m}$ ) with a flow rate $0.4 \mathrm{~mL} \mathrm{~min}^{-1}$. The column oven temperature was maintained at $40^{\circ} \mathrm{C}$. The injection volume was $5 \mu \mathrm{L}$. The MS conditions were as follow: negative ionization mode; acquisition range: $110-1180 \mathrm{Da}$; source temperature: $120^{\circ} \mathrm{C}$; desolvation gas temperature: $350{ }^{\circ} \mathrm{C}$; desolvation gas flow: $500 \mathrm{~L} \mathrm{~h}^{-1}$; extraction cone voltage: $0.5 \mathrm{~V}$; capillary voltage: $2.6 \mathrm{kV}$. Leucine enkephalin was used as the lock mass. Instrument control and data acquisition were performed using Masslynx 4.1 (Waters Corporation $^{\circledR}$, Milford, Massachusetts, USA) software. Acetonitrile, chromatography grade methanol, and ultrapure water $(18.2 \mathrm{M} \Omega \mathrm{cm}$ ) were used for analysis.

\section{Fungal strains}

Three clinical isolates and one purchased from American Type Culture Collection (ATCC) for each species of Candida spp. were studied: C. albicans (CA ATCC 90028, CA2, CA3, CA4); C. glabrata (CG ATCC 2001, CG2, CG3, CG4); C. tropicalis (CT ATCC 13803, CT2, CT3, CT4), C. parapsilosis complex-C. parapsilosis (CP ATCC 22019, CP1) and C. orthopsilosis (CO ATCC 96141, CO1) and C. krusei (CK ATCC 6258, CK2, CK3, CK4). C. albicans (ATCC 10231) was used for the hyphae formation assay.

The clinical strains were donated to the Microbiology Laboratory of the Medicine School in São José do Rio Preto for the purposes of scientific research through written consent of the donors. The use of these strains was approved by the Human Research Ethics Committee of FAMERP, project identification code 152/2006 (December $\left.6^{\text {th }}, 2006\right)$, Medicine School in Sao José do Rio Preto (FAMERP).
Determination of minimum inhibitory concentration (MIC)

The antifungal activity of EE was evaluated by determining the MIC using the microplate dilution technique according to the procedures described by Clinical and Laboratory Standards Institute (CLSI) ${ }^{20}$ with modifications. Roswell Park Memorial Institute (RPMI)1640 medium (Sigma-Aldrich $^{\circledast}$, Saint Louis, MO, USA) adjusted to $\mathrm{pH}$ 7.0 with MOPS (acid 3-[N-morpholino]propanesulfonic acid) buffer (Sigma-Aldrich ${ }^{\circledR}$, Saint Louis, MO, USA) was added to each well. Solutions of EE $(0.1 \mathrm{~mL})$ were added at concentrations ranging from 1000 to $7.8 \mu \mathrm{g} \mathrm{mL} \mathrm{m}^{-1}$. A suspension $(0.1 \mathrm{~mL})$ containing $2.5 \times 10^{3}$ yeast $\mathrm{mL}^{-1}$ was added to each well. Amphotericin B (Sigma-Aldrich ${ }^{\circledR}$, Saint Louis, MO, USA) and fluconazole (Sigma-Aldrich ${ }^{\circledR}$, Saint Louis, MO, USA) were used as antimicrobial positive controls. Controls including culture medium, yeast growth, EE, and solvent were also prepared. The microplates were incubated at $37{ }^{\circ} \mathrm{C}$ for $48 \mathrm{~h}$. After incubation, $20 \mu \mathrm{L}$ of an aqueous $2 \%$ solution of 2,3,5-triphenyltetrazolium chloride (TTC) (Sigma-Aldrich ${ }^{\circledR}$, Saint Louis, MO, USA) were added, and the plates were incubated at $37^{\circ} \mathrm{C}$ for $2 \mathrm{~h} .{ }^{7,21}$ All experiments were performed in triplicate.

The MIC results of EE strains were used to select the most sensitive strains (one ATCC and one clinical isolate for each species) for evaluation of antifungal activity as previously described. ${ }^{20}$

Determination of minimum fungicidal concentration (MFC)

The MFC was determined by adding an aliquot from each well that showed antifungal activity to Petri dishes containing Sabouraud Dextrose Agar (SDA) $\left(\right.$ DIFCO $^{\circledR}$, Le Pont de Claix, France). These experiments were performed in triplicate. The MFC was defined as the lowest concentration of $\mathrm{EE}$ and Fr that resulted in no visible growth on the solid medium. ${ }^{7,21}$

Inhibition of $C$. albicans hyphae formation

C. albicans (ATCC 10231) was cultured for $24 \mathrm{~h}$ to obtain filamentous yeast. Then, the yeast was suspended at a concentration of $2.5 \times 10^{3}$ cells $\mathrm{mL}^{-1}$ in phosphatebuffered saline (PBS, $\mathrm{pH}$ 7.2). Twenty microliters of this suspension were added to microplate wells containing RPMI 1640 medium (Sigma-Aldrich ${ }^{\circledR}$, Saint Louis, MO, USA) with $10 \%$ fetal bovine serum and $1 \%$ gentamicin. EE solution was evaluated at concentrations ranging from 1000 to $7.8 \mu \mathrm{g} \mathrm{mL}{ }^{-1}$. After 12 and $24 \mathrm{~h}$, reductions in hyphal growth were visualized using an inverted light microscope (400×). Amphotericin B (Sigma-Aldrich ${ }^{\circledR}$, Saint Louis, 
MO, USA) (16 $\left.\mu \mathrm{g} \mathrm{mL}^{-1}\right)$ was used as the positive control. Additional controls included fungal growth, solvent, sterile EE solution, and culture medium. ${ }^{7}$

Time-kill assay

The time-kill assay was carried out according to Santos-Filho et al. ${ }^{22}$ with modifications. One ATCC strain and one clinical strain of each Candida species (CA ATCC 90028, CA3, CK ATCC 6258, CK4, CG ATCC 2001, CG3, CT ATCC 13803, CT3, CP ATCC 22019, CP1, CO ATCC and CO1) was evaluated. Two times the MIC of EE were added to Sabouraud Dextrose broth (DIFCO ${ }^{\circledR}$, Le Pont de Claix, France), containing $2.5 \times 10^{3}$ colony-forming unit (CFU) $\mathrm{mL}^{-1}$ of Candida spp. and incubated at $37^{\circ} \mathrm{C}$. At different time intervals $(0,1,2,4$, $8,12,24,36$, and $48 \mathrm{~h}) 100 \mu \mathrm{L}$ aliquots were removed and diluted 1:100 twice in sterile PBS. Each EE-cell suspension was spread onto SDA (DIFCO ${ }^{\circledR}$, Le Pont de Claix, France) (incubation $48 \mathrm{~h}$ at $37^{\circ} \mathrm{C}$ ) for subsequent counting of CFU. As the positive control was used amphotericin B (SigmaAldrich $^{\circledR}$, Saint Louis, MO, USA) and cell suspensions without addition of EE were the negative control.

\section{Mature biofilm}

The biofilm adhesion method was performed as previously described by Pitangui et al. ${ }^{23}$ with modifications. CA ATCC 90028, CA3, CK 6258, CK4, CP ATCC 22019 , and CP1 were evaluated. Inoculum $(0.1 \mathrm{~mL}$, $5.0 \times 10^{8}$ yeast $\left.\mathrm{mL}^{-1}\right)$ suspended in saline $(0.9 \%)$ was added to the microplate wells ( 96 wells), then incubated at $37{ }^{\circ} \mathrm{C}$ for $2 \mathrm{~h}$ with stirring at $80 \mathrm{rpm}$. After the preadhesion period, the supernatant was removed and $0.1 \mathrm{~mL}$ of RPMI medium (Sigma-Aldrich ${ }^{\circledR}$, Saint Louis, MO, USA) was added to each microplate well. The plates were incubated for $48 \mathrm{~h}$, with the medium replaced after $24 \mathrm{~h}$. Following incubation, the supernatant was removed, and the wells were washed with $0.1 \mathrm{~mL}$ of $0.9 \%$ saline. EE solution $(0.1 \mathrm{~mL})$ was added to each well at 50 times the MIC. Amphotericin B (Sigma-Aldrich ${ }^{\circledR}$, Saint Louis, MO, USA) was used as the positive control. Other controls included culture medium, yeast growth, EE solution, and solvent. The microplates incubated for $24 \mathrm{~h}$ at $37^{\circ} \mathrm{C}$, then developed with 2,3-bis(2-methoxy-4-nitro-5-sulfophenyl)5-[carbonyl (phenylamino)]-2H-tetrazolium hydroxide $\left(\mathrm{XTT}^{\circledR}{ }^{\circledR}\right.$ Sigma-Aldrich $^{\circledR}$, Saint Louis, MO, USA).

\section{Cell lines}

HepG2 (ATCC ${ }^{\circledR}$ HB-8065'M , Fiocruz, Rio de Janeiro,
Brazil) and MRC-5 (ATCC ${ }^{\circledR} \mathrm{CCl}-171^{\mathrm{TM}}$, Fiocruz, Rio de Janeiro, Brazil) were used to determine cytotoxicity (half maximal inhibitory concentration, $\mathrm{IC}_{50}$ ). The cells were maintained in flasks with a $12.50 \mathrm{~cm}^{2}$ surface area containing $10 \mathrm{~mL}$ of culture medium and incubated at $37^{\circ} \mathrm{C}$ in a $5 \% \mathrm{CO}_{2}$ chamber. The culture medium consisted of Dulbecco's Modified Eagle Medium (DMEM, Vitrocell ${ }^{\circledR}$, Campinas, São Paulo, Brazil) supplemented with $10 \%$ fetal bovine serum, gentamicin sulfate $\left(50 \mathrm{mg} \mathrm{L}^{-1}\right)$ (SigmaAldrich $^{\circledR}$, Saint Louis, MO, USA), and amphotericin B (Sigma-Aldrich ${ }^{\circledast}$, Saint Louis, MO, USA) $\left(2 \mathrm{mg} \mathrm{L}^{-1}\right)$.

\section{Cytotoxicity assay}

To determine cytotoxicity, cells were collected using trypsin/ethylenediaminetetraacetic acid (EDTA) (Vitrocell ${ }^{\circledR}$, Campinas, São Paulo, Brazil), centrifuged (2,000 rpm for $5 \mathrm{~min}$ ), and counted using a Neubauer chamber. The cell concentration was adjusted to $7.5 \times 10^{4}$ cells $\mathrm{mL}^{-1}$ in DMEM. Two hundred microliters of this suspension were plated in each well at $1.5 \times 10^{4}$ cells per well. The microplates were then incubated at $37{ }^{\circ} \mathrm{C}$ in a $5 \% \mathrm{CO}_{2}$ incubator for $24 \mathrm{~h}$ to facilitate cell adhesion. Serial dilutions of EE, FrC, and FrD were prepared to obtain concentrations ranging from 3.9 to $1000 \mu \mathrm{g} \mathrm{mL}{ }^{-1}$. Diluted solutions were added to the wells after removal of the incubation medium and non-adherent cells. The plates were then incubated for $24 \mathrm{~h}$. Cytotoxicity was determined by addition of $30 \mu \mathrm{L}$ of resazurin followed by a $6 \mathrm{~h}$ incubation period. The plates were analyzed using a microplate reader $\left(\right.$ BioTek $^{\circledast}$, Winoosky, VT, USA) with excitation and emission wavelengths of 530 and $590 \mathrm{~nm}$, respectively. The $\mathrm{IC}_{50}$ was defined as the highest concentration of each fraction that resulted in at least $50 \%$ cell viability. All experiments were performed in triplicate. Five percent of dimethyl sulfoxide (DMSO) were used as the control. ${ }^{24}$

\section{Results and Discussion}

\section{UPLC-ESI-QTOF-MSE analysis}

Compounds were identified based on retention time, fragmentation pattern, and accurate mass (chemical formula). Figure 1 shows a total ion chromatogram (TIC) of EE obtained in negative mode. Table 1 summarizes the identities of compounds 1-10 in EE as determined by mass spectrometry (high resolution $\mathrm{MS}$ and $\mathrm{MS} / \mathrm{MS}^{\mathrm{n}}$ ). Data from the acquired spectra were compared with specialized literature data. ${ }^{25-29}$ Based on these spectral comparisons, the following secondary metabolites were identified: two mono- $C$ - (luteolin and apigenin 
derivatives) and two di- $C$-glycosyl flavones (luteolin derivatives), and six phenylpropanoid glycosides: three di- $O$-feruloyl-di- $O$-acetyl sucrose isomers (e.g., smiglaside A) and three di-O-feruloyl-tri- $O$-acetyl sucrose isomers (e.g., smiglaside C). The main peak observed in the TIC $\left(\mathrm{t}_{\mathrm{R}}=6.90 \mathrm{~min}\right)$ corresponded to a di- $O$-feruloyl-tri- $O$-acetyl sucrose isomer.

The spectra of both mono- $C$ - and di- $C$-glycosyl flavones (Table 1, compounds 1-4) showed typical sugar moiety fragments resulting from cleavage of the $C$-hexosyl and $C$-pentosyl rings (deprotonated ions at $\mathrm{m} / \mathrm{z}[\mathrm{M}-\mathrm{H}-60]^{-}$, $[\mathrm{M}-\mathrm{H}-90]^{-},[\mathrm{M}-\mathrm{H}-120]^{-},[\mathrm{M}-\mathrm{H}-180]^{-}$, and $\left.[\mathrm{M}-\mathrm{H}-210]^{-}\right) .{ }^{29,30}$

Compounds 3 and $\mathbf{4}$ showed deprotonated molecule signals $\left([\mathrm{M}-\mathrm{H}]^{-}\right)$at $\mathrm{m} / \mathrm{z} 447.0922$ and 431.0983 , respectively. The observed fragmentation patterns were characteristic of $C$-glycosyl flavones. The $\mathrm{MS}^{2}$ data showed fragment ion signals at $m / z 357$ and 327 for compound $\mathbf{3}$ and at $m / z, 341$ and 311 for compound $\mathbf{4}$, which corresponded to loss of 90 and $120 \mathrm{Da}$ from the $[\mathrm{M}-\mathrm{H}]^{-}$ions, respectively, which is typical of a hexose substitution in the aglycone moiety. These data supported assignments of luteolin8-C-glucoside (orientin) for compound $\mathbf{3}$ and apigenin8-C-glucoside (vitexin) for compound 4. ${ }^{26,27}$ Flavonoid $C$-glycosylation has almost exclusively been found at positions 6 or $8^{29}$ and according to a previous study ${ }^{26}$ the relative intensities of the $[\mathrm{M}-\mathrm{H}-90]^{-}$fragment ions were 22 and $100 \%$ for orientin and isoorientin (luteolin-6$C$-glucoside), respectively, and 8 and $42 \%$ for vitexin and isovitexin (apigenin-6-C-glucoside), respectively, supporting identification of orientin and vitexin in EE (Table 1). The fragment ion signal at $\mathrm{m} / \mathrm{z} 285$ for compound $\mathbf{3}$ may correspond to kaempferol (flavonol) or luteolin (flavone) aglycone moieties ( $\mathrm{Y}^{-}$fragment ion), but data from previous

Table 1. Proposed phenolic compounds detected in C. nardus EE by UPLC-ESI-QTOF-MS(/MS)

\begin{tabular}{|c|c|c|c|c|c|c|c|c|}
\hline Compound & $\begin{array}{l}\text { Retention } \\
\text { time / min }\end{array}$ & $\begin{array}{l}\text { Empirical } \\
\text { formula }\end{array}$ & $\begin{array}{l}{[\mathrm{M}-\mathrm{H}]^{-}} \\
\text {observed }\end{array}$ & $\begin{array}{l}{[\mathrm{M}-\mathrm{H}]^{-}} \\
\text {calculated }\end{array}$ & $\begin{array}{l}\text { Error / } \\
\mathrm{ppm}\end{array}$ & $\begin{array}{l}\text { MS/MS fragment ions } \\
\text { (relative abundance / \%) }\end{array}$ & Putative name & Reference \\
\hline 1 & 3.46 & $\mathrm{C}_{26} \mathrm{H}_{28} \mathrm{O}_{15}$ & 579.1335 & 579.1350 & 2.6 & $\begin{array}{c}519.1381(12), 489.1046(52), \\
459.0822(42), 429.0785(29), \\
399.0722(75), 369.0647(88), \\
133.0230(3)\end{array}$ & $\begin{array}{l}\text { luteolin-6- } \\
C \text {-arabinoside- } \\
\text { 8- } C \text {-glucoside }\end{array}$ & 25,26 \\
\hline 2 & 3.87 & $\mathrm{C}_{25} \mathrm{H}_{28} \mathrm{O}_{14}$ & 549.1209 & 549.1244 & 6.4 & $\begin{array}{c}531.1587(2), 489.0969(7) \\
459.0842(40), 429.0727(30) \\
399.0607(80), 369.0598(44), \\
133.0262(1)\end{array}$ & $\begin{array}{l}\text { luteolin-6,8-di- } \\
C \text {-arabinoside }\end{array}$ & 26 \\
\hline 3 & 3.94 & $\mathrm{C}_{21} \mathrm{H}_{20} \mathrm{O}_{11}$ & 447.0922 & 447.0927 & 4.0 & $\begin{array}{c}357.0461(22), 339.0600(13), \\
327.0445(100), 299.0549(28), \\
297.0301(26), 285.0474(18), \\
133.0299(1)\end{array}$ & $\begin{array}{l}\text { luteolin- } \\
\text { 8- } C \text {-glucoside } \\
\text { (orientin) }\end{array}$ & 26,27 \\
\hline 4 & 4.25 & $\mathrm{C}_{21} \mathrm{H}_{20} \mathrm{O}_{10}$ & 431.0983 & 431.0978 & 0.2 & $\begin{array}{c}341.0851(9), 323.0531(19), \\
311.0475(81), 283.0561(100), \\
281.0421(3), 269.0467(2)\end{array}$ & $\begin{array}{l}\text { apigenin- } \\
\text { 8- } C \text {-glucoside } \\
\quad(\text { vitexin })\end{array}$ & 26 \\
\hline 5 & 6.18 & $\mathrm{C}_{36} \mathrm{H}_{42} \mathrm{O}_{19}$ & 777.2248 & 777.2242 & 0.8 & $\begin{array}{c}735.1852(3), 717.1985(6), \\
601.1769(5), 559.1522(5), \\
193.0482(14), 175.0382(100)\end{array}$ & $\begin{array}{l}\text { di- } O \text {-feruloyl-di- } \\
O \text {-acetyl sucrose }\end{array}$ & 28 \\
\hline 6 & 6.32 & $\mathrm{C}_{36} \mathrm{H}_{41} \mathrm{O}_{19}$ & 777.2206 & 777.2242 & 4.6 & $\begin{array}{c}735.1752(3), 717.1892(7), \\
601.1716(6), 559.1657(8), \\
193.0491(12), 175.0380(100)\end{array}$ & $\begin{array}{l}\text { di- } O \text {-feruloyl-di- } \\
O \text {-acetyl sucrose }\end{array}$ & 28 \\
\hline 7 & 6.63 & $\mathrm{C}_{36} \mathrm{H}_{42} \mathrm{O}_{19}$ & 777.2195 & 777.2242 & 6.0 & $\begin{array}{c}735.2078(1), 717.1902(1) \\
601.1771(30), 559.1614(10) \\
193.012(14), 175.389(100)\end{array}$ & $\begin{array}{l}\text { di- } O \text {-feruloyl-di- } \\
O \text {-acetyl sucrose }\end{array}$ & 28 \\
\hline 8 & 6.90 & $\mathrm{C}_{38} \mathrm{H}_{44} \mathrm{O}_{20}$ & 819.2283 & 819.2348 & 7.9 & $\begin{array}{c}777.2292(8), 601.1830(8), \\
513.1558(3), 193.0468(6), \\
175.0377(100)\end{array}$ & $\begin{array}{l}\text { di- } O \text {-feruloyl-tri- } O \text { - } \\
\text { acetyl sucrose }\end{array}$ & 28 \\
\hline 9 & 7.05 & $\mathrm{C}_{38} \mathrm{H}_{44} \mathrm{O}_{20}$ & 819.2291 & 819.2348 & 7.0 & $\begin{array}{c}777.2177(8), 759.2155(9) \\
601.1768(8), 193.0481(35) \\
175.0377(100)\end{array}$ & $\begin{array}{l}\mathrm{di}-O \text {-feruloyl-tri- } O \text { - } \\
\text { acetyl sucrose }\end{array}$ & 28 \\
\hline 10 & 7.21 & $\mathrm{C}_{38} \mathrm{H}_{44} \mathrm{O}_{20}$ & 819.2303 & 819.2348 & 5.5 & $\begin{array}{c}777.1954(3), 759.2157(2) \\
601.1773(8), 193.0506(48) \\
175.0399(100)\end{array}$ & $\begin{array}{l}\text { di- } O \text {-feruloyl-tri- } O \text { - } \\
\text { acetyl sucrose }\end{array}$ & 28 \\
\hline
\end{tabular}




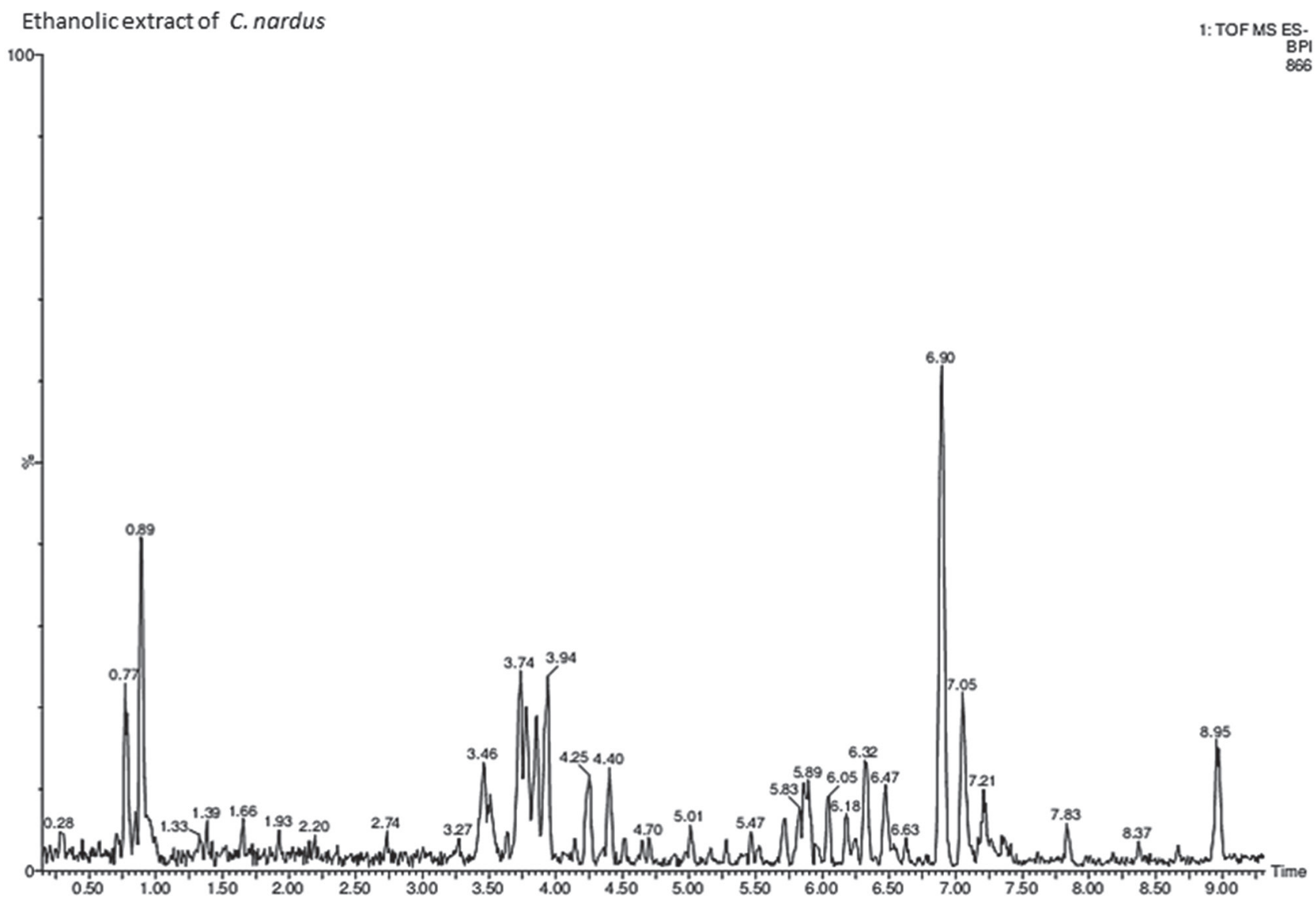

Figure 1. Total ion chromatogram (TIC) of EE obtained in the negative ion mode by UPLC-ESI-QTOF-MS(/MS).

study ${ }^{29}$ showed that the fragment ion signal at $\mathrm{m} / \mathrm{z} 133$ was characteristic of luteolin aglycone ( $\mathrm{Y}^{-}$fragment ion). The fragment ion signal at $m / z 269$ for compound $\mathbf{4}$ corresponded to the apigenin aglycone moiety ( $\mathrm{Y}^{-}$fragment ion). Other major fragment ion signals typical for orientin were observed at $m / z 299$ and 297 and at $m / z 283$ and 281 vitexin, and were attributed to loss of 148 and $150 \mathrm{Da}^{27}$

Compound 2 showed deprotonated molecule signals at $\mathrm{m} / 2549.1209[\mathrm{M}-\mathrm{H}]^{-}$and fragment ion signals in $\mathrm{MS}^{2}$ spectra at $m / z 489,459,429,399$, and 369, which corresponded to losses of 60, 90, 120, $150(60+90)$, and $180(60+120) \mathrm{Da}$ from the $[\mathrm{M}-\mathrm{H}]^{-}$ion, which were characteristic of a di- $C$-pentosyl flavone. These data supported identification of this compound as luteolin-6,8-di-C-arabinoside. ${ }^{29,30}$ Compound 1 showed deprotonated molecule signals at $m / z 579.1335[\mathrm{M}-\mathrm{H}]^{-}$. The observed fragmentation pattern in the $\mathrm{MS}^{2}$ spectrum corresponded to a $C$-hexosyl$C$-pentosyl flavone with fragment ion signals at $m / z 519,489$, $459,429,399$, and 369 , corresponding to losses of 60,90 , $120,150(60+90), 180(60+120)$, and $210(90+120) \mathrm{Da}$ from the $[\mathrm{M}-\mathrm{H}]^{-}$ion, respectively. These data supported identification of this compound as luteolin-6- $C$-arabinosyl8-C-glucoside. ${ }^{26,27}$ Previous studies of di- $C$-glycoside flavones reported that 6- $C$-pentosyl-8- $C$-hexosyl substitution resulted in higher abundance of the $[\mathrm{M}-\mathrm{H}-90]^{-}$fragment ion relative to the $[\mathrm{M}-\mathrm{H}-120]^{-}$fragment ion. For example, luteolin-6- $C$-arabinosyl-8- $C$-glucoside showed a higher abundance of the $[\mathrm{M}-\mathrm{H}-90]^{-}$fragment ion at $\mathrm{m} / z 489$ (52\%) than that of the $[\mathrm{M}-\mathrm{H}-120]^{-}$fragment ion at $m / z 459$ (17\%), while luteolin-8-C-glicosyl-6- $C$-arabinoside showed a higher abundance of the $[\mathrm{M}-\mathrm{H}-120]^{-}$fragment ion at $m / z, 459(74 \%)$ than that of the $[\mathrm{M}-\mathrm{H}-90]^{-}$fragment ion at $\mathrm{m} / z 489(23 \%){ }^{26}$ Therefore, the data from Table 1 suggest a 6- $C$-pentosyl-8- $C$-hexosyl substitution pattern for compound $\mathbf{1}$. As discussed for orientin, the presence of the ion fragment signals at $\mathrm{m} / \mathrm{z}, 133$ for compounds $\mathbf{1}$ and $\mathbf{2}$ supports luteolin as the aglycone moiety.

Compounds 5-7 showed deprotonated molecule signals $[\mathrm{M}-\mathrm{H}]^{-}$at $\mathrm{m} / z$ 777.2248, 777.2206, and 777.2195, and fragment ion signals at $\mathrm{m} / \mathrm{z} 601$ due to loss of $176 \mathrm{Da}$, which represented a feruloyl moiety. The fragment ion signals at $\mathrm{m} / \mathrm{z}, 175$ and 193 corresponded to a feruloyl moiety ${ }^{25}$ and the other fragment ion signals shown in Table 1 supported identification of these compounds as di- $O$-feruloyldi- $O$-acetyl sucrose isomers (e.g., smiglaside A). ${ }^{28,31}$ Compounds 8-10 showed deprotonated molecule signals $[\mathrm{M}-\mathrm{H}]^{-}$at $\mathrm{m} / \mathrm{z} 819.2283,819.2291$, and 819.2303 , and the fragment ion signals at $m / z 175$ and 193 corresponded to a 
feruloyl moiety ${ }^{25}$ which supported identification of these compounds as di- $O$-feruloyl-tri- $O$-acetyl sucrose isomers (e.g., smiglaside $\mathrm{C}){ }^{28}$

Previous studies have identified phenylpropanoid derivatives (e.g., chlorogenic acid and caffeic acid) and glycosyl flavones (e.g., isoorientin) in the Cymbopogon genus. These compounds are structurally and biosynthetically related to the compounds identified in the of EE C. nardus. However, no studies have evaluated non-volatile secondary metabolites in C. nardus. ${ }^{30}$

FrD was the most active EE fraction against Candida strains. TIC data of FrD were compared with data from a previous study ${ }^{28}$ and identification of the compounds in FrD was performed identically during evaluation of EE of C. nardus. The identified secondary metabolites included the same six phenylpropanoid glycosides found in EE: three di- $O$-feruloyl-di- $O$-acetyl sucrose isomers (e.g., smiglaside A) and three di- $O$-feruloyl-tri- $O$-acetyl sucrose isomers (e.g., smiglaside C). Fractionation resulted in collection of each of these compounds in FrD and the main peak observed in the TIC $\left(t_{R}=6.90 \mathrm{~min}\right)$ corresponded to a di- $O$-feruloyl-tri- $O$-acetyl sucrose isomer, as observed in EE.

\section{MIC and MFC determination of EE}

The data showed that EE exhibited antifungal activity with MIC values ranging from 62.5 to $500 \mu \mathrm{g} \mathrm{mL} \mathrm{L}^{-1}$, including in isolates resistant to fluconazole and amphotericin-B (Table S1, Supplementary Information (SI) section). The lowest MIC value $\left(62.5 \mu \mathrm{g} \mathrm{mL}^{-1}\right)$ in response to treatment with EE was observed for $C$. glabrata clinical isolates. EE showed a fungistatic profile against all tested isolates with MFC $>500 \mu \mathrm{g} \mathrm{mL}^{-1}$. The solvent and growth controls produced satisfactory results.

These analyses showed that EE was active against all strains, except CK-ATCC and CO1. These results are very important, since EE was able to inhibit different species of Candida, including those resistant to fluconazole, the main antifungal agent used in medical practice. In addition, the results of MFC analysis showed that EE did not induce cell death, but only promoted growth inhibition. These results may be related to fungistatic mechanisms of action.

The antimicrobial potential exerted by plant extracts from the genus Cymbopogon has been observed previously. The study performed by Oloyede ${ }^{32}$ evaluated the performance of the aqueous extract of the leaves of $C$. citratus against Escherichia coli, Staphylococcus aureus, Bacillus cereus, and Salmonella typhi, and showed excellent results.

The antimicrobial activity of $C$. nardus is reportedly due to properties of its essential oils. Previous studies demonstrated the antifungal potential of the essential oil of C. nardus against Candida species. ${ }^{7,33,34}$ However, the antifungal properties and chemical composition of the EE of C. nardus have not been evaluated. Thus, this study was the first to evaluate these parameters, which may be of interest in the pharmaceutical and medical fields.

We highlighted the results obtained from testing of the C. glabrata species. The MIC values for this species were the lowest compared to those for the other strains evaluated in this study, and all strains of this species were resistant to fluconazole. C. glabrata is considered the secondmost pathogenic yeast that affects humans, after only C. albicans. ${ }^{35}$ This species is directly involved in invasive fungal infections ranging from local to blood infections. In the case of systemic infections, treatment is challenging due to a dearth of therapeutic options. ${ }^{19}$

The antimicrobial performance of products derived from medicinal plants may be explained by the presence of secondary metabolites. Previous studies have demonstrated the antimicrobial activity of secondary metabolites against different types of microorganisms. ${ }^{11}$ The major classes of secondary metabolites are phenolic compounds, phenolic acids, quinones, saponins, flavonoids, tannins, phenazine, coumarins, lignans, neolignans, alkaloids, and terpenoids. ${ }^{36}$

Chemical analysis of $\mathrm{EE}$ and $\mathrm{FrD}$ in this study showed the presence of $C$ - and di- $C$-glycosylated flavones, and glycosylated phenylpropanoid derivatives, which directly exert antifungal activity. The antifungal activity of flavonoids in plant species has been studied extensively. Furthermore, glycosylated phenylpropanoids have been shown to inhibit the growth of several species of Candida. ${ }^{37}$

\section{MIC and MFC determination of the Fr}

Only FrC and FrD exhibited antifungal activity against of the majority of the Candida strains. FrD showed the lowest MIC value $\left(15.6 \mu \mathrm{g} \mathrm{mL}^{-1}\right)$ against $C$. glabrata ATCC (Table S2, SI section). FrA, FrB, FrE, FrF, and FrG showed no antifungal activity, with MIC $>500 \mu \mathrm{gL}^{-1}$.

Comparison between $\mathrm{EE}$ and each of the fractions of EE demonstrated that $\mathrm{FrD}$ was the most active against C. krusei, C. glabrata, C. tropicalis, and C. orthopsilosis. These results indicated that the phenylpropanoid glycosides identified in this study were the most likely substances responsible for EE antifungal activity, since they were concentrated in FrD after fractionation, and FrD exhibited greater anti-Candida activity than EE. The MIC of FrD against CG-ATCC $\left(15.6 \mu \mathrm{g} \mathrm{mL}^{-1}\right)$ was lower than that of $\mathrm{EE}\left(250 \mu \mathrm{g} \mathrm{mL} \mathrm{m}^{-1}\right)$. Moreover, FrD exhibited greater activity against the $C$. glabrata clinical isolate $\left(31.2 \mu \mathrm{g} \mathrm{mL}^{-1}\right)$ than

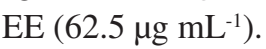


Previous studies ${ }^{37-40}$ have shown that phenylpropanoids glycoside exert pronounced antioxidant activity, antimicrobial activity, cytotoxic activity against some tumor cell lines, and strong anticandidal activity. A previous study ${ }^{37}$ demonstrated that the antifungal activity of phenylpropanoid glycosides such as verbascoside and isoverbascoside $\left(\mathrm{MIC}=1.5 \mu \mathrm{g} \mathrm{mL}^{-1}\right.$ ) against several Candida strains was similar to the conventional antifungals, miconazole and amphotericin $\mathrm{B}\left(\mathrm{MIC}=0.5 \mu \mathrm{g} \mathrm{mL}^{-1}\right.$ ).

The mechanisms of action of natural products vary. The cytoplasmic membrane is the most common site of action of secondary metabolites, with action on this structure resulting in extravasation of cellular contents and fungal death. The interaction with genetic material and protein synthesis is also a predisposing factor for promotion of therapeutic actions of natural products. Interaction of genetic material with secondary metabolites promotes changes in deoxyribonucleic acid (DNA), resulting in ineffective transcription, leading to aberrant cellular function and cell death. ${ }^{36}$

Phenylpropanoid glycosides may act through formation of intramolecular interactions (for example, hydrogen bonding) which disrupts the physicochemical properties of the fungal cell, including membrane permeability, water solubility, and lipophilicity. ${ }^{41}$

\section{Inhibition of $C$. albicans hyphae formation}

EE was able to inhibit the transition of $C$. albicans from yeast to the hyphal form. Microscopic observation of EE-treated fungal cells demonstrated the absence of filamentous cells at concentrations ranging from 250 to $1000 \mu \mathrm{g} \mathrm{mL}^{-1}$ after 12 and $24 \mathrm{~h}$ (Figure 2).

These results are relevant to the pharmaceutical and medical fields because hyphae forming ability is the main risk factor during infections. ${ }^{42}$ No previous studies have shown that $\mathrm{EE}$ of $C$. nardus can inhibit hyphae formation in C. albicans.
Several studies evaluating natural products observed prevention of hyphal development and proliferation of C. albicans. Chevalier et al..$^{43}$ evaluated the capacity of the aqueous extract of Solidago virgaurea to inhibit C. albicans (ATCC 10231) hyphae formation and showed that this extract inhibited hyphal proliferation.

Vediyappan et al. ${ }^{44}$ showed that an extract of Gymnema sylvestre $\left(50 \mu \mathrm{g} \mathrm{mL}^{-1}\right)$ inhibited C. albicans hyphae formation within $24 \mathrm{~h}$ of contact. Araújo et al. ${ }^{45}$ showed that the methanolic extract of scapes of $S$. nitens inhibited C. albicans NCPF 3153 hyphae formation at concentrations of 500, 250, and $125 \mu \mathrm{g} \mathrm{mL}-1$ within 12 to $24 \mathrm{~h}$.

The observation that EE inhibited hyphae formation suggested that this extract may act through control of yeast morphology, resulting in decreased proliferation, thus facilitating the activity of the active components present in the extract.

\section{Time-kill assay}

The effects of EE on Candida growth are shown in Figures 3-8. The results confirmed the fungistatic mechanism observed during evaluation of MFC, since treatment with EE led to reduced numbers of colonies compared to that with control treatments. Furthermore, EE showed activity similar to that of amphotericin-B against all tested strains.

EE inhibited growth of CG ATCC 2001, CG3, CP1, and CO ATCC 96141 to a greater extent at $48 \mathrm{~h}$ (final time) than amphotericin B. These results are important because they further demonstrated the inhibitory capacity of EE against different Candida species, especially the C. glabrata strains, which were fluconazole-resistant $\left(\mathrm{MIC}>64 \mu \mathrm{g} \mathrm{mL} L^{-1}\right)$. The data found in this work corroborate with study developed by Toledo et al. ${ }^{7}$ whereby the essential oil of $C$. nardus showed similar growth against the same of Candida species.

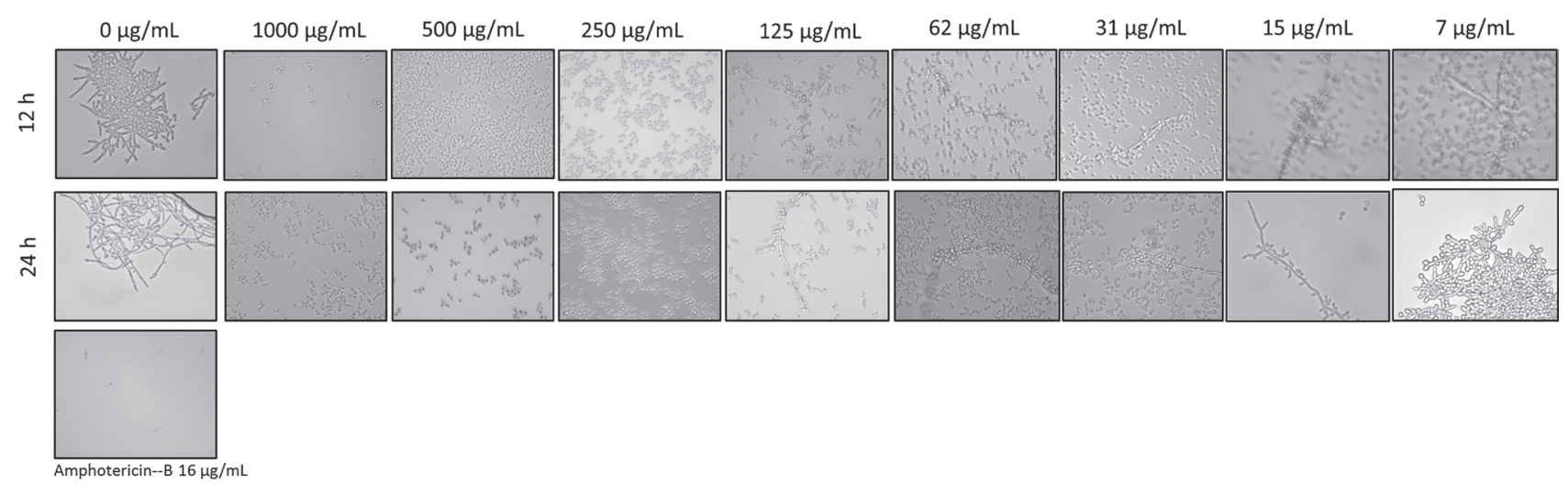

Figure 2. Inhibitory effect of EE of C. nardus on the transition of C. albicans from yeast to the hyphal form (photomicrographs by inverted light microscopic under $400 \times$ magnification). 
CA ATCC 90028

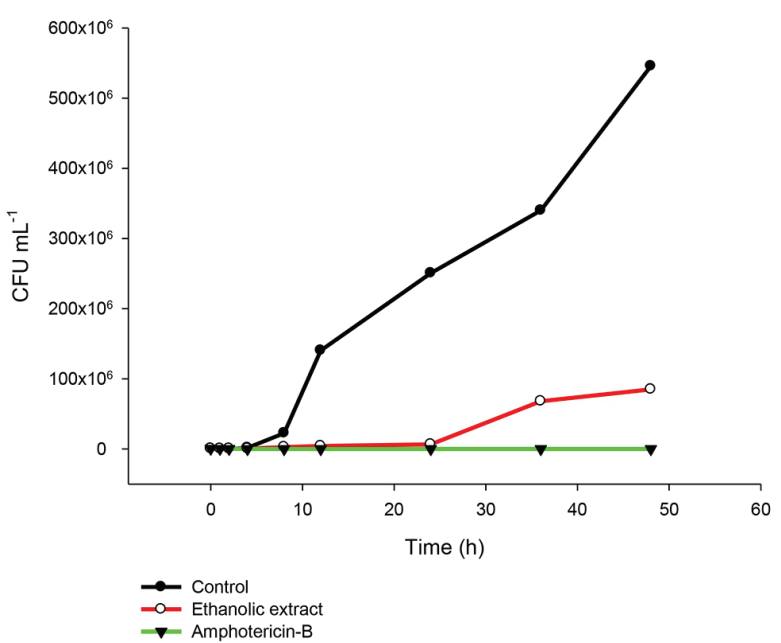

CA3

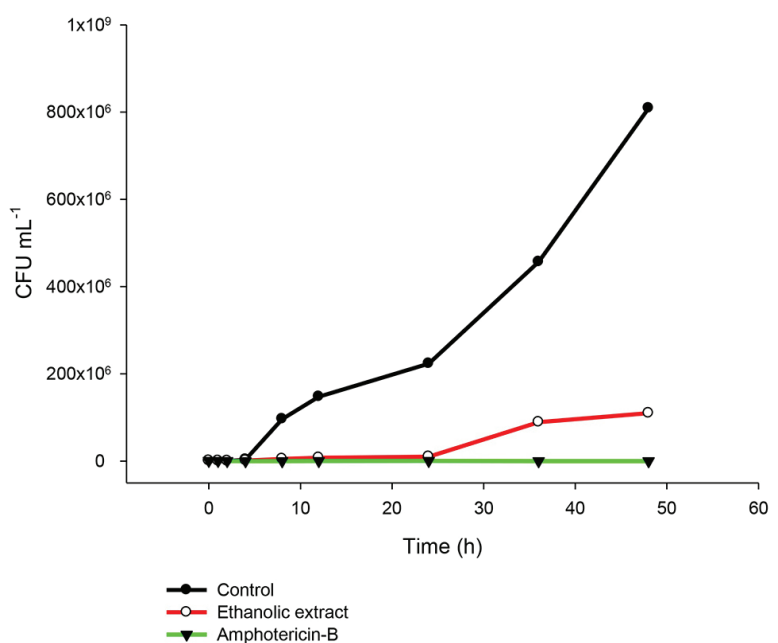

Figure 3. Time-kill curves of C. albicans ATCC 90028 and CA3 following exposure to the EE of C. nardus and amphotericin-B. Control represents the untreated Candida cell. Note: time zero value $=2.5 \times 10^{3} \mathrm{CFU} \mathrm{mL}^{-1}$.

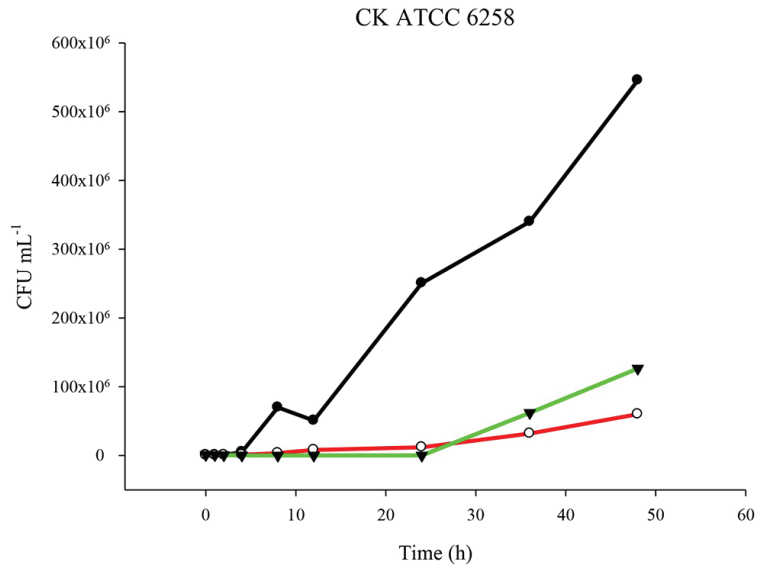

$\rightarrow$ Control

$-\infty$ Ethanolic extrac

$\checkmark$ Amphotericin-B

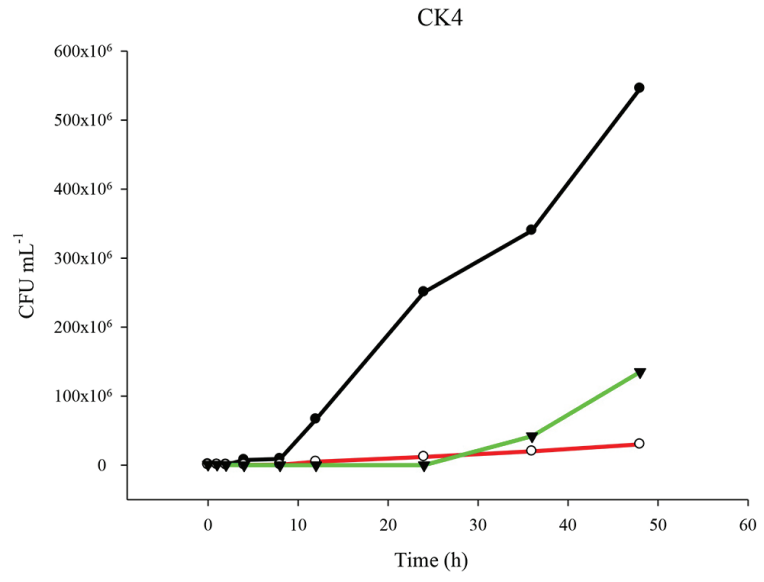

$\longrightarrow$ Control
$\sim-$ Ethanolic extract

Figure 4. Time-kill curves of C. krusei ATCC 6258 and CK4 following exposure to the EE of C. nardus and amphotericin-B. Control represents the

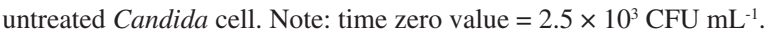
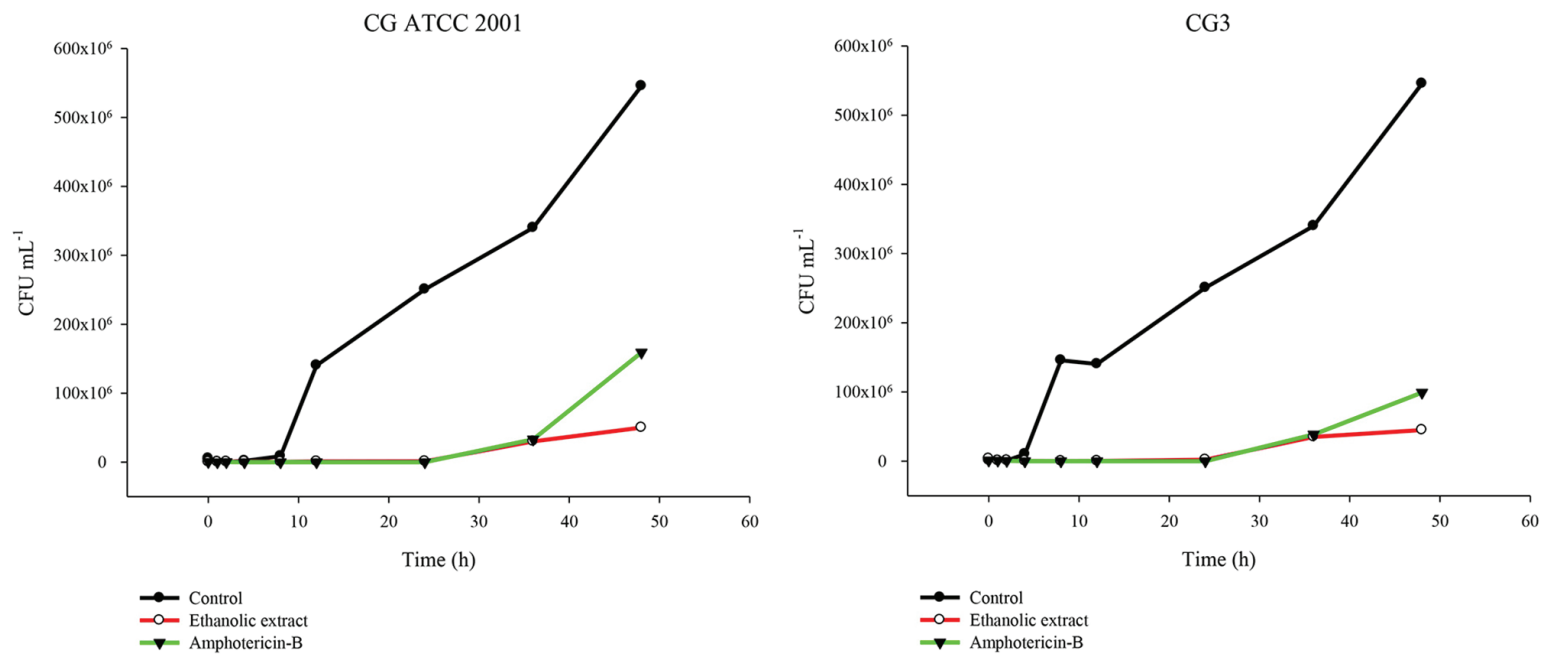

Figure 5. Time-kill curves of C. glabrata ATCC 2001 and CG3 following exposure to the EE of C. nardus and amphotericin-B. Control represents the untreated Candida cell. Note: time zero value $=2.5 \times 10^{3} \mathrm{CFU} \mathrm{mL}^{-1}$. 
CT ATCC 13803

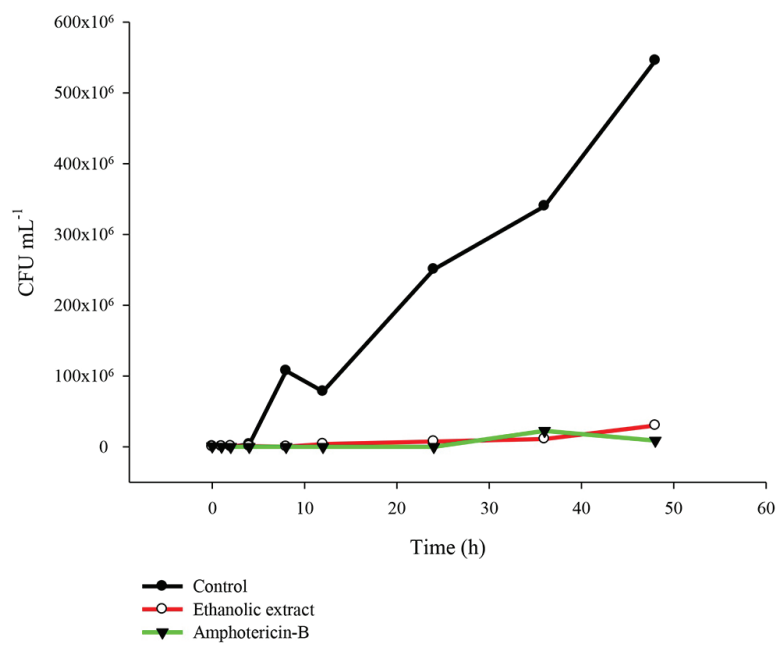

CT3

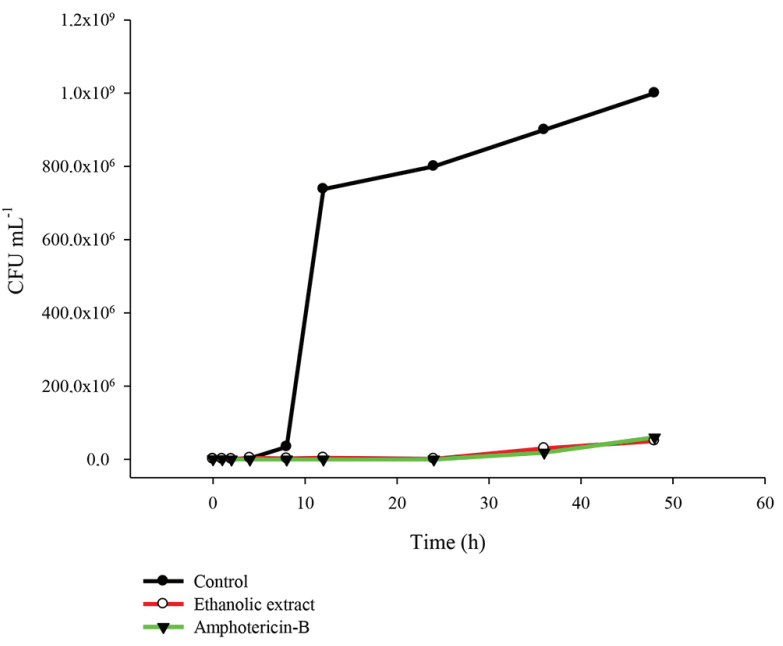

Figure 6. Time-kill curves of C. tropicalis ATCC 13801 and CT3 following exposure to the EE of C. nardus and amphotericin-B. Control represents the untreated Candida cell. Note: time zero value $=2.5 \times 10^{3} \mathrm{CFU} \mathrm{mL}^{-1}$.
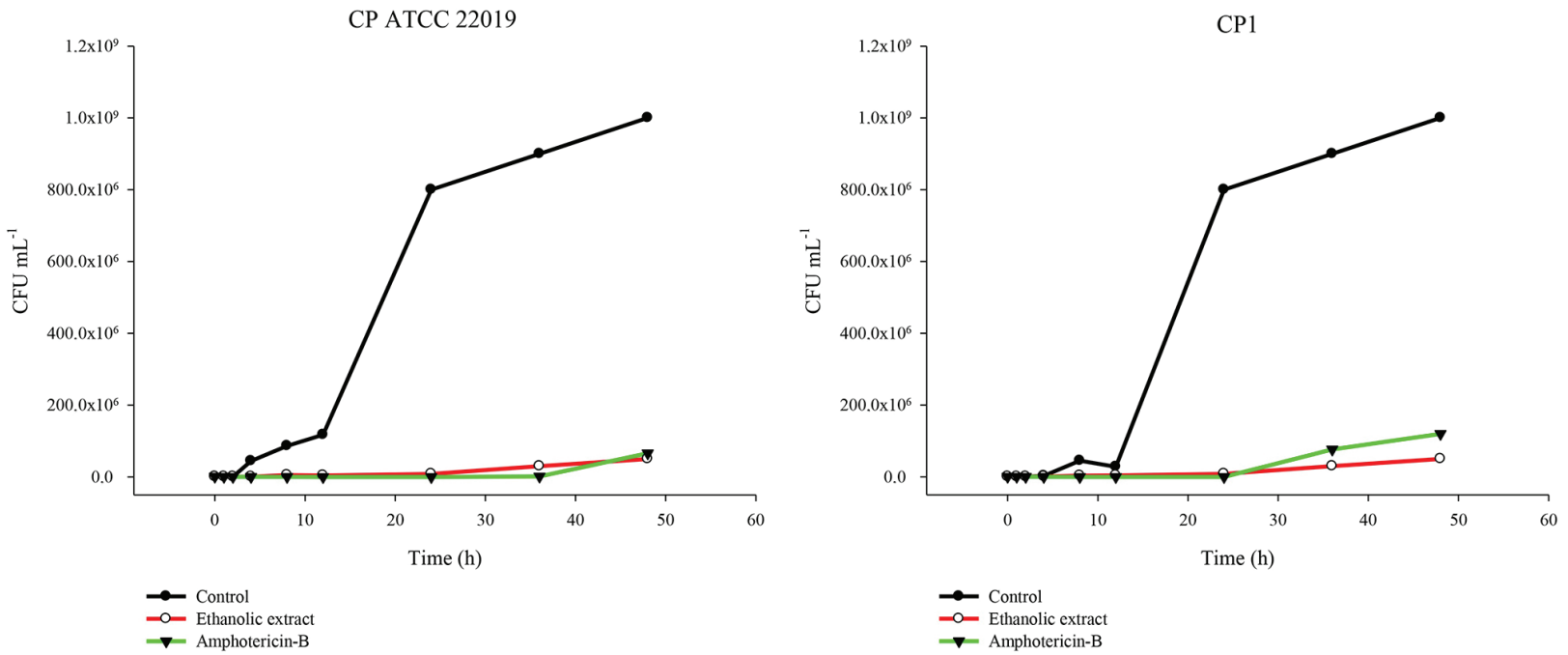

Figure 7. Time-kill curves of C. parapsilosis ATCC 22019 and CP1 following exposure to the EE of C. nardus and amphotericin-B. Control represents the untreated Candida cell. Note: time zero value $=2.5 \times 10^{3} \mathrm{CFU} \mathrm{mL}^{-1}$.
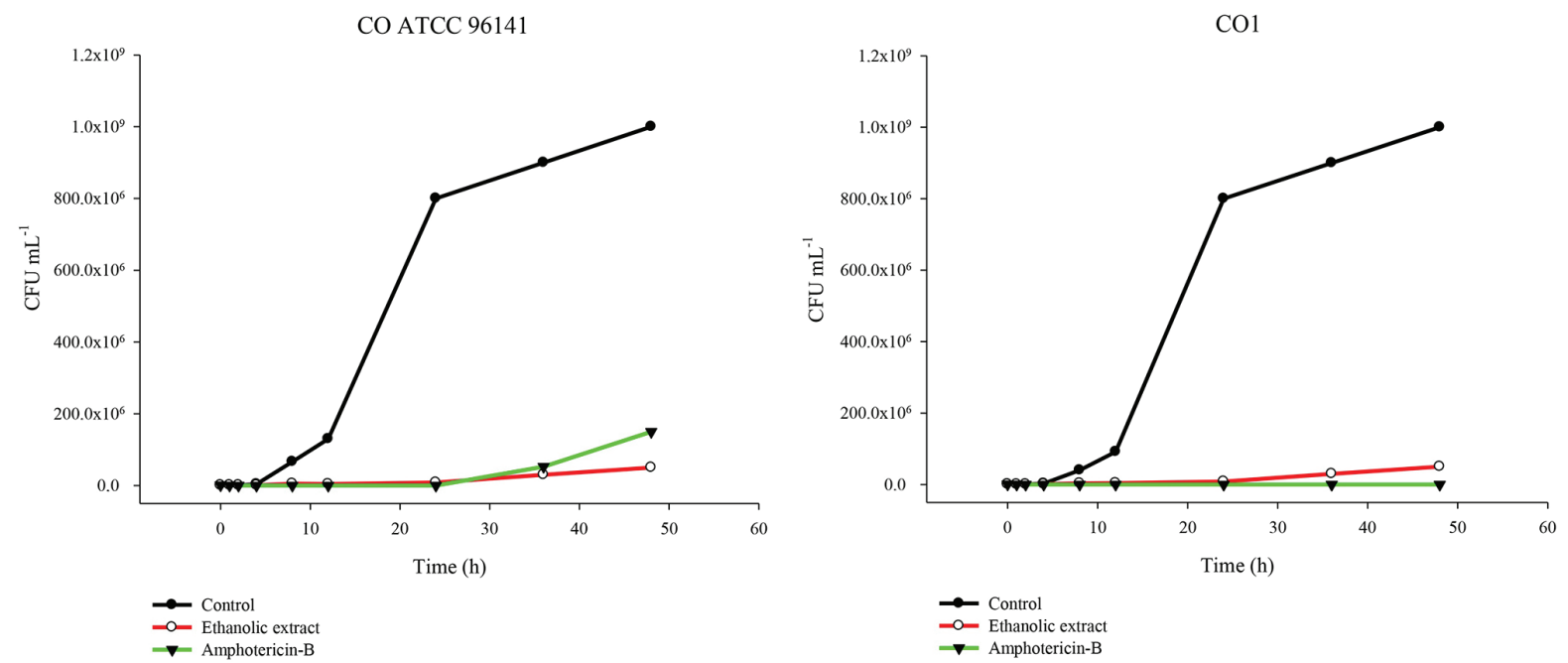

Figure 8. Time-kill curves of C. orthopsilosis ATCC 96141 and CO1 following exposure to the EE of C. nardus and amphotericin-B. Control represents the untreated Candida cell. Note: time zero value $=2.5 \times 10^{3} \mathrm{CFU} \mathrm{mL}^{-1}$. 


\section{Effect of EE on mature biofilms of Candida species}

The results showed that EE inhibited $C$. albicans, C. krusei, and C. parapsilosis mature biofilms. The concentrations (fifty times the MIC value) of EE able to eradicate mature biofilms of ATCC strains of $C$. albicans, C. krusei and C. parapsilosis were $25 \mathrm{mg} \mathrm{mL}^{-1}$. For clinical strains of $C$. krusei (CK4) and C. parapsilosis (CP1) the inhibition concentration was $12.5 \mathrm{mg} \mathrm{mL}^{-1}$ of EE. EE showed no biofilm inhibition (> $6.25 \mathrm{mg} \mathrm{mL}^{-1}$ ) against strain of $C$. albicans (CA3). As this was the first report evaluating $\mathrm{EE}$ of $C$. nardus, these results are of great potential importance in the scientific field.

Biofilms represent a significant impact on public health, especially during establishment of chronic fungal diseases. ${ }^{46}$ Biofilm formation is an important virulence factor associated with the Candida species, and treatments that prevent biofilms are limited because biofilms have a complex structure composed of polysaccharide extracellular matrix, which limits targeting of antifungal agents into biofilms. Furthermore, extensive communication among cells resulting in production of virulence-related molecules and the presence of a high fungal burden contribute the lack of efficacy of antifungal drugs. ${ }^{45}$

Natural products have been shown to exhibit anti-biofilm potential. A study by Sangetha et $\mathrm{al} .{ }^{47}$ demonstrated that the methanolic extract of leaves of Cassia spectabilis inhibited C. albicans biofilm formation at $6.25 \mathrm{mg} \mathrm{mL}^{-1}$. However, this extract did not effectively eliminate mature biofilms.

A study performed by Ramos et al. ${ }^{48}$ showed that the methanolic extract of Syngonanthus nitens was ineffective against mature $C$. krusei biofilms. To overcome this issue, the authors employed a nanoparticle drug delivery system. Based on these findings, the $50 \times$ MIC value observed in our study suggested a satisfactory inhibition profile.

\section{Cytotoxic evaluation}

The $\mathrm{IC}_{50}$ values of $\mathrm{EE}$ and $\mathrm{FrD}$ are summarized in Table 2. Both EE and FrD exhibited higher $\mathrm{IC}_{50}$ values against HepG2 cells than MRC-5 cells. The differences in responses between the cells could be related to the greater metabolic capacity of HepG2 cells, which mimic the metabolic status of human liver cells. These cells have the ability to retain the activities of various phase I and phase II enzymes which play important roles in elimination and detoxification of these classes of compounds in vivo. ${ }^{49}$

\section{Conclusions}

In conclusion, EE from leaves of $C$. nardus contained
Table 2. Cytotoxic activity $\left(\mathrm{IC}_{50}\right)$ of $\mathrm{EE}$ and $\mathrm{FrD}$ against MRC-5 and HepG2 cell lines

\begin{tabular}{lccc}
\hline \multicolumn{4}{c}{$\mathrm{IC}_{50}{ }^{a} /\left(\mu \mathrm{g} \mathrm{mL}^{-1}\right)$} \\
\hline Cell line & EE & FrD & Control $^{\mathrm{b}}$ \\
\hline HepG-2 & $348.9 \pm 12.1$ & $135.7 \pm 1.9$ & $>1000$ \\
MRC-5 & $181.3 \pm 11.6$ & $69.4 \pm 4.9$ & $>1000$ \\
\hline
\end{tabular}

${ }^{\mathrm{a}} \mathrm{IC}_{50}$ : concentration required to inhibit $50 \%$ of cell growth (average \pm standard error (SE)); ${ }^{b}$ dimethylsulfoxide. EE: ethanol extract; FrD: fraction D.

compounds that exerted significant antifungal activity. The identified secondary metabolites in EE were phenolic compounds, including $C$ - and di- $C$-glycosylated flavones, and glycosylated phenylpropanoid derivatives. These metabolites were abundant in FrD, and likely explained the antifungal potency of this fraction. Biological assays showed that EE exhibited activity against several strains of Candida species, including those resistant to fluconazole. Furthermore, EE was able to inhibit the main virulence factors associated with Candida species such as biofilms and $C$. albicans hyphae formation. In previous study, the essential oil of $C$. nardus showed superior activity than EE against the main virulence factors of Candida species. However, the EE exhibited lower MIC values than essential oil against planktonic Candida cells.

\section{Supplementary Information}

Supplementary data (tables) are available free of charge at http://jbcs.sbq.org.br as PDF file.

\section{Acknowledgments}

This work was supported by São Paulo Research Foundation, São Paulo, Brazil (grants No. 2013/195760, 2015/23959-7 and 2016/08559-5). This study was financed in part by the Coordenação de Aperfeiçoamento de Pessoal de Ensino Superior-Brasil (CAPES)-Finance code-001.

\section{Author Contributions}

Luciani Gaspar de Toledo was responsible for conceptualization, data curation, formal analysis, funding acquisition, investigation, methodology, project administration, validation, writing-original draft, writingreview and editing; Matheus Aparecido dos Santos Ramos for conceptualization, data curation, investigation, methodology, writing-original draft; Larissa Spósito for investigation, methodology; Elza Maria Castilho for project administration, supervision; Fernando Rogério 
Pavan for data curation, methodology, supervision; Érica de Oliveira Lopes for data curation, investigation methodology; Isabel Cristiane da Silva for data curation; Guilherme Julião Zocolo for data curation, investigation methodology, validation, supervision; Paulo Riceli Vasconcelos Ribeiro for investigation, methodology; Fernando Bombarda Oda for data curation, formal analysis, investigation, methodology; Juhan Augusto Scardelato Pereira for methodology; André Gonzaga dos Santos for conceptualization, data curation, formal analysis, methodology, supervision, validation, writing-original draft; Taís Maria Bauab for conceptualization, data curation, formal analysis, funding acquisition, methodology, supervision, writing-original draft; Margarete Teresa Gottardo de Almeida for conceptualization, data curation, formal analysis, funding acquisition, methodology, project administration, validation, writing-original draft, writingreview and editing.

\section{References}

1. Chanthai, S.; Prachakoll, S.; Ruangviriyachai, C.; Luthria, D. L.; J. AOAC Int. 2012, 95, 763.

2. Boukhatem, M. N.; Ferhat, M. A.; Kameli, A.; Saidi, F.; Kebir, H. T.; Libyan J. Med. 2014, 9, 25431.

3. Sfeir, J.; Lefrançois, C.; Baudoux, D.; Derbré, S.; Patricia, L.; J. Evidence-Based Complementary Altern. Med. 2013, 2013, 269161.

4. Kim, J.-R.; Haribalan, P.; Son, B.-K.; Ahn, Y.-J.; J. Econ. Entomol. 2012, 105, 1329.

5. Olivero-Verbel, J.; Nerio, L. S.; Stashenko, E. E.; Pest Manage. Sci. 2010, 66, 664.

6. Duarte, A.; Alves, A. C.; Ferreira, S.; Silva, F.; Domingues, F. C.; Food Res. Int. 2015, 77, 244.

7. Toledo, L. G.; Ramos, M. A. S.; Spósito, L.; Castilho, E. M.; Pavan, F. R.; Lopes, E. O.; Zocolo, G. J.; Silva, F. A. N.; Soares, T. H.; Santos, A. G.; Bauab, T. M.; Almeida, M. T. G.; Int. J. Mol. Sci. 2016, 17, 1252.

8. Trindade, L. A.; Oliveira, J. A.; de Castro, R. D.; Lima, E. O.; Clin. Oral Invest. 2015, 19, 2223.

9. Alshami, I.; Alharbi, A. E.; Asian Pac. J. Trop. Biomed. 2014, 4, 104

10. Barbieri, D. S. V.; Tonial, F.; Lopez, P. V. A.; Maia, B. H. L. N. S.; Santos, G. D.; Ribas, M. O.; Glienke, C.; Vicente, V. A.; Arch. Oral Biol. 2014, 59, 887.

11. Zore, G. B.; Thakre, A. D.; Rathod, V.; Karuppayil, S. M.; Mycoses 2011, 54, 99.

12. Capoci, I. R. G.; da Cunha, M. M.; Bonfim-Mendonça, P. S.; Ghiraldi-Lopes, L. D.; Baeza, L. C.; Kioshima, E. S.; Svidzinski, T. I. E.; Rev. Inst. Med. Trop. Sao Paulo 2015, 57, 509.
13. Chai, L. Y. A.; Netea, M. G.; Tai, B. C.; Khin, L. W.; Vonk, A. G.; Teo, B. W.; Schlamm, H. T.; Herbrecht, R.; Donnelly, J. P.; Troke, P. F.; Kullberg, -J.; J. Antimicrob. Chemother. 2013, 68, 1655.

14. Calabrese, E. C.; Castellano, S.; Santoriello, M.; Sgherri, C.; Quartacci, M. F.; Calucci, L.; Warrilow, A. G. S.; Lamb, D. C.; Kelly, S. L.; Milite, C.; Granata, I.; Sbardella, G.; Stefancich, G.; Maresca, B.; Porta, A.; J. Antimicrob. Chemother. 2013, 68, 1111.

15. Deorukhkar, S. C.; Saini, S.; Mathew, S.; Int. J. Microbiol. 2014, 2014, 456878.

16. Scorzoni, L.; de Lucas, M. P.; Mesa-Arango, A. C.; Fusco-Almeida, A. M.; Lozano, E.; Cuenca-Estrella, M.; Mendes-Giannini, M. J.; Zaragoza, O.; PLoS One 2013, 8, e60047.

17. Lum, K. Y.; Tay, S. T.; Le, C. F.; Lee, V. S.; Sabri, N. H.; Velayuthan, R. D.; Hassan, H.; Sekaran, S. D.; Sci. Rep. 2015, $5,9657$.

18. Kato, H.; Yoshimura, Y.; Suido, Y.; Shimizu, H.; Ide, K.; Sugiyama, Y.; Matsuno, K.; Nakajima, H.; J. Infect. Chemother. 2019, 25, 341.

19. Sardi, J. C. O.; Scorzoni, L.; Bernardi, T.; Fusco-Almeida, A. M.; Mendes Giannin, M. J. S.; J. Med. Microbiol. 2012, 62, 10.

20. Clinical and Laboratory Standards Institute (CLSI); Reference Method for Broth Dilution Antifungal Susceptibility Testing of Yeasts, $3^{\text {rd }}$ ed.; CLSI document M27-A3; Clinical and Laboratory Standards Institute: Wayne, 2008.

21. Ramos, M. A. S.; de Toledo, L. G.; Calixto, G. M. F.; Bonifácio, B. V.; Araújo, M. G. F.; dos Santos, L. C.; de Almeida, M. T. G.; Chorilli, M.; Bauab, T. M.; Int. J. Mol. Sci. 2016, 17, 1368.

22. Santos-Filho, N. A.; Lorenzon, E. N.; Ramos, M. A. S.; Santos, C. T.; Piccoli, J. P.; Bauab, T. M.; Fusco-Almeida, A. M.; Cilli, E. M.; Toxicon 2015, 103, 160.

23. Pitangui, N. S.; Sardi, J. C. O.; Silva, J. F.; Benaducci, T.; Silva, R. A. M.; Rodríguez-Arellanes, G.; Taylor, M. L.; Mendes-Giannini, M. J. S.; Fusco-Almeida, A. M.; Biofouling 2012, 28, 711.

24. O'Brien, J.; Wilson, I.; Orton, T.; Pognan, F.; Eur. J. Biochem. 2000, 267, 5421.

25. Abu-Reidah, I. M.; Arráez-Román, D.; Segura-Carretero, A.; Fernández-Gutiérrez, A.; Food Res. Int. 2013, 51, 354.

26. Singh, A.; Kumar, S.; Bajpai, V.; Reddy, T. J.; Rameshkumar, K. B.; Kumar, B.; Rapid Commun. Mass Spectrom. 2015, 29 , 1095.

27. March, R. E.; Lewars, E. G.; Stadey, C. J.; Miaob, X.; Zhaob, X.; Metcalfe, C. D. A.; Int. J. Mass Spectrom. 2005, 248, 61.

28. Chen, T.; Li, J. X.; Xu, Q.; Phytochemistry 2000, 53, 1051.

29. Cuyckens, F.; Ma, Y. L.; Pocsfalvi, G.; Claeys, M.; Analusis 2000, 28, 888.

30. Cao, J.; Yin, C.; Qin, Y.; Cheng, Z.; Chen, D.; J. Mass Spectrom. 2014, 49, 1010.

31. Kuo, Y. H.; Hsu, Y. W.; Liaw, C. C.; Lee, J. K.; Huang, H. C.; Kuo, L. M. Y.; J. Nat. Prod. 2005, 68, 1475. 
32. Oloyede, O. I.; J. Nat. Prod. 2009, 2, 98.

33. Benzaid, C.; Belmadani, A.; Djeribi, R.; Rouabhia, M.; Antibiotics 2019, 8, 10.

34. Sahal, G.; Nasseri, B.; Ebrahimi, A.; Bilkay, I. S.; Biotechnol. Lett. 2019, 41, 511.

35. Quintin, J.; Asmar, J.; Matskevich, A. A.; Lafarge, M.; Ferrandon, D.; J. Immunol. 2013, 190, 2818.

36. Gyawali, R.; Ibrahim, S. A.; Novel Antimicrob. Agents Strategies 2014, 46, 219.

37. Pereira, A. M. S.; Hernandes, C.; Pereira, S. I. V.; Bertoni, B. W.; França, S. C.; Pereira, P. S.; Taleb-Contini, S. H.; Chem.Biol. Interact. 2014, 224, 136.

38. Zhang, L.; Liao, C. C.; Huang, H. C.; Shen, Y. C.; Yang, L. M.; Kuo, Y. H.; Phytochemistry 2008, 69, 1398.

39. Wang, W. X.; Li, T. X.; Ma, H.; Zhang, J. F.; Jia, A. Q.; J. Ethnopharmacol. 2013, 149, 527.

40. Abdel-Mageed, W. M.; Backheet, E. Y.; Khalifa, A. A.; Ibraheim, Z. Z.; Ross, S. A.; Fitoterapia 2012, 83, 500.

41. Kuhn, B.; Mohr, P.; Stahl, M.; J. Med. Chem. 2010, 53, 2601.

42. Mayer, F. L.; Wilson, D.; Hube, B.; Virulence 2013, 4, 119.

43. Chevalier, M.; Medioni, E.; Prêcheur, I.; J. Med. Microbiol. 2012, 61, 1016 .
44. Vediyappan, G.; Dumontet, V.; Pelissier, F.; D’Enfert, C.; PLoS One 2013, 8, e74189.

45. Araújo, M. G. F.; Pacífico, M.; Vilegas, W.; dos Santos, L. C.; Icely, P. A.; Miró, M. S.; Scarpa, M. V. C.; Bauab, T. M.; Sotomayor, C. E.; Med. Mycol. 2013, 51, 673.

46. Barsoumian, A. E.; Mende, K.; Sanchez Jr., C. J.; Beckius, M. L.; Wenke, J. C.; Murray, C. K.; Akers, K. S.; BMC Infect. Dis. 2015, 15, 223.

47. Sangetha, S.; Zuraini, Z.; Suryani, S.; Sasidharan, S.; Micron 2009, 40, 439.

48. Ramos, M. A. S.; Calixto, G.; Toledo, L. G.; Bonifácio, B. V.; Santos, L. C.; Almeida, M. T. G.; Chorilli, M.; Bauab, T. M.; Int. J. Nanomed. 2015, 10, 7455.

49. Knasmüller, S.; Parzefall, W.; Sanyal, R.; Ecker, S.; Schwab, C.; Uhl, M.; Mersch-Sundermann, V.; Williamson, G.; Hietsch, G.; Langer, T.; Darroudi, F.; Natarajan, A. T.; Mutat. Res., Fundam. Mol. Mech. Mutagen. 1998, 402, 185.

Submitted: October 25, 2019

Published online: May 20, 2020 